\title{
Challenges of Nigerian Accounting Postgraduate Students in Taking up Stance in Ph.D. Theses in Bayero University, Kano, Nigeria
}

\author{
Sani Yantandu Uba ${ }^{1}$, Julius Irudayasamy ${ }^{1} \&$ Carmel Antonette Hankins ${ }^{2}$ \\ ${ }^{1}$ Department of English Language \& Literature, Dhofar University, Salalah, Oman \\ ${ }^{2}$ Foundation Program English Language Unit, Dhofar University, Salalah, Oman \\ Correspondence: Sani Yantandu Uba, Department of English Language \& Literature, Dhofar University, Salalah, \\ Oman.
}

Received: January 11, 2021

Accepted: February 26, 2021

Online Published: March 1, 2021

doi:10.5430/ijhe.v10n4p175

URL: https://doi.org/10.5430/ijhe.v10n4p175

\begin{abstract}
This paper investigates the use of stance linguistic features in accounting Ph.D. theses in a Nigerian university. We adopted a mixed-methods approach by combining a textual analysis of the theses and explored the context of writing of the participants similar to Swale's textography approach. We compiled three corpora: Bayero University corpus of six accounting Ph.D. theses (BUK corpus); a United Kingdom corpus of six accounting PhD theses (UK corpus) and a corpus of eleven journal articles of accounting (JAA corpus). The results of textual analysis indicate that there is a higher frequency of hedges in all the three corpora than other stance features, followed by boosters, then attitudinal markers, and explicit self-mention features. One striking finding from the BUK corpus is that the authors are rarely used self-mention features compared to authors from other two corpora. However, the result of the chi-square indicates that the differences among the three corpora's use of stance features are insignificant. The contextual data suggests that non-teaching of English for specific purposes and the traditional practices of Bayero University might be some of the possible factors that constrained authors' use of stance linguistic features. We recommend introduction of teaching English for specific purposes on postgraduate programmes in Nigerian universities.
\end{abstract}

Keywords: stance linguistic features, BUK corpus, UK corpus, JAA corpus, Ph.D. thesis

\section{Introduction}

The importance of disciplinary discourses, epistemology and linguistic features vary across disciplines, genres, and context has been discussed (Becher 1987b; Becher \& Trowler, 2001; Thompson 2001; Swales, 1990, 1998: Hyland, 2007, 2005c; \& Widdowson, 1998). Fairclough, (1992a) states that socio-cultural factors may enable or constrain the production and reception of a discourse. Many research studies of stance linguistic features have been conducted across genres, disciplines, including cross-cultural studies. However, some of these studies are focused on research article genres across disciplines (McGrath, 2016; Silver, 2003; Afshar, Moradi, \& Hamzavi, 2014); some pay more attention to undergraduate academic essay (Laura and Lancaster, 2014); still others concentrate on comparative analysis of stance linguistic features across disciplines (Hyland, 2005c, Ebeling \& Wickens, 2012); others focus their research within a discipline (McGrath \& Kuteeva, 2012; Charles, 2006a \& Kondowe, 2014). However, a research on the discipline of accounting regarding use of stance linguistic features has not been reported in $\mathrm{Ph}$. $\mathrm{D}$. theses in Nigerian context. We have argued that the construction of knowledge, and linguistic features vary across disciplines, and that social contexts may enable or constrain the production and reception of a discourse. Here we investigate what stance linguistic features are frequently used by accounting Ph.D. authors in their theses at Bayero University.

\section{Literature Review}

\subsection{Stance}

Stance is viewed as personal attitudes, including emotions and assessments of someone's knowledge (Gray \& Biber 2012). Others view stance as social interactions which are articulated linguistically on the basis of socio-cultural values (Du Bois, 2007). We align with the view of Du Bois since it acknowledges the discourse community's values or beliefs in taking up positions. 


\subsection{Hyland's Theoretical Framework}

Scholars have provided theoretical frameworks for stance linguistic features (Biber, 2006; Hyland, 1996a; Holmes, 1988; Crismore, Markkanen, \& Steffensen 1993; Conrad \& Biber, 2000; Martin, 2000; Hunston, 2000). Following this, there is no categorical definition of the concept because many scholars used different concepts or terms. These previous studies are mainly concerned with some particular aspects of stance such as affect, intensity, epistemic modality and so forth. Furthermore, majority of those studies are concerned with public genres such as media.

Hyland's (2005a) theoretical framework has some limitations in that he included only PhDs and Masters' dissertations across six disciplines rather than incorporating a wider range of academic genres. Nevertheless, he makes an attempt to incorporate all those concepts into one - that of stance. One of the strengths of his model is specifically its focus on the written academic genres across disciplines, which differentiates it from other theoretical frameworks. The framework focuses extensively on written academic genres. However, we should note that lexical items may overlap and could perform more than one function at a time. Chafe (1986: 262) also argues that 'various linguistic expressions slide across more than one of the various types'. In spite of some of the weaknesses of his framework, we have adopted it based on the above reasons, and the limitations of other frameworks. His framework (1999a \& 2005b) states that stance has four elements: Hedges, Boosters, Attitude markers and Self-mention. (see appendix 1 for details)

\subsection{Studies on Stance Linguistic Features}

There has been a growing interest in exploring stance features across different genres. Ahmad and Mehrjooseresh (2012) investigate stance in thesis abstracts. Pho (2008) studies authorial stance in a corpus of 30 abstracts of research articles. Auria (2008) investigates and compares stance linguistic features across soft science disciplines. Laura and Lancaster (2014) investigate stance linguistic features in a corpus-based textual comparative study in the academic writing of first year undergraduate students and advanced students. Bondi (2008) focuses his study on hedges and boosters across two disciplines: History and Economics. Kondowe's (2014) study concentrates on hedges and boosters. Hyland (2005b) also investigates stance linguistic features in research articles. Charles (2006a) carried out study on reporting clauses across two disciplines: Material sciences and Politics written by native speakers of English. Nivales (2011) studies hedging in undergraduate essays. Peacock (2006) examines boosting across disciplines. Afshar, Moradi, and Hamzavi (2014) focus their study on hedges in research articles across disciplines. $\mathrm{Hu}$ and Cao (2011) focus their research on boosting and hedging in Applied Linguistics. In addition, Afshar, Asakereh and Rahimi (2014) study hedging in the academic essays of non-native speakers and native of English across three fields. Samaie, Khosravian and Boghayeri (2014) investigate frequency of hedges in literature. Furthermore, some researchers focus their study on self-mentions features (Hyland 2002c; McGrath, 2016; Hobbs, 2014; Shehzad, 2007; Martinez, 2005; \& Duenas, 2007).

This review suggests that there are some gaps and indeed some suggest further research across genres, contexts and disciplines. For example, a Ph.D. genre has been neglected in terms of published research of stance features especially in the Nigerian context. In the light of this, this study aims to investigate what stance linguistic features are frequently used in Ph.D. theses (the discipline of accounting) in a Nigerian university. It also aims to address the following questions:

1. What stance linguistic features are frequently used in the accounting Ph.D. theses?

2. How do epistemological, institutional, and disciplinary factors impact on their use of stance linguistic features?

\section{Methodology}

As noted above, this study is specifically concerned with the use of stance linguistic features within the discipline of accounting, investigating what stance linguistic features are typically used in the construction of knowledge in the accounting Ph.D. theses in the Nigerian context. We have two types of participants in this study: three accounting $\mathrm{Ph} . \mathrm{D}$. supervisors and six accounting Ph.D. authors. The primary focus of this study is a textual analysis of six Nigerian accounting Ph.D. theses. However, we explored the context of writing of the Ph.D. authors (Hyland, 2002 \& Baynham, 2002). Following this, we compiled two more corpora (see section 2.1 below), and textography approach, interviews and data from publications, such as journal articles from the discipline of accounting. We first describe how we constructed the three corpora.

\subsection{The Corpora}

Researchers should consider a number of factors in corpus building, such as purpose, size and so on (Kennedy, 2014; 
Thompson, 2001; \& Baker, 2006). Scholars also argue about the corpus design; however, it is not our focus here for details on this topic, see Stubbs, (1996); Hoey, (1986); Engwall, (1994); Hunston, (2002); Kenney, (1998); and Baker, (2006).

As noted above our primary concern is accounting Ph.D. theses in a Nigerian university. We first developed a corpus of six accounting Ph.D. theses of 218, 611 words (hereafter BUK corpus). We then created two more corpora: a corpus of six accounting Ph.D. theses of 290, 170 words (hereafter UK corpus); and A corpus of eleven journal articles of 93,256 words (here after JAA corpus) both written in English speaking countries.

We have mentioned above that in this study we adopted a corpus-based approach, supplemented by data on the institutional and disciplinary context. In corpus-based textual analysis, we used WordSmith Tools (Scott, 2004). In quantitative corpus analysis, we followed two stages: generating wordlist and comparing relative frequencies of linguistic items or using ANOVA to make possible conclusions on the linguistic items being investigated (Scott \& Tribble, 2006; \& Scott, 1997). Regarding the qualitative analysis dimension, as discussed above, we conducted interviews and analysed their responses using thematic analysis (Miles \& Huberman, 1984; \& Creswell, 2007).

\section{Results}

We have discussed in the above section, that in order to get more insights and triangulate our study, we combine both quantitative corpus-based analysis and a qualitative institutional and contextual approach. We first present the quantitative corpus-based results of the study.

\subsection{Quantitative Corpus-Based Results}

We first present the results of textual analysis of Bayero University's theses, and then present the comparative corpus-based analysis of all the three corpora, aiming at exploring more explanations regarding the use of stance linguistic features within the discipline of accounting. Again, we aim to investigate whether there are differences in the use of stance linguistic features within this discipline particularly regarding the notions of native speakers and non-native speakers of English writers

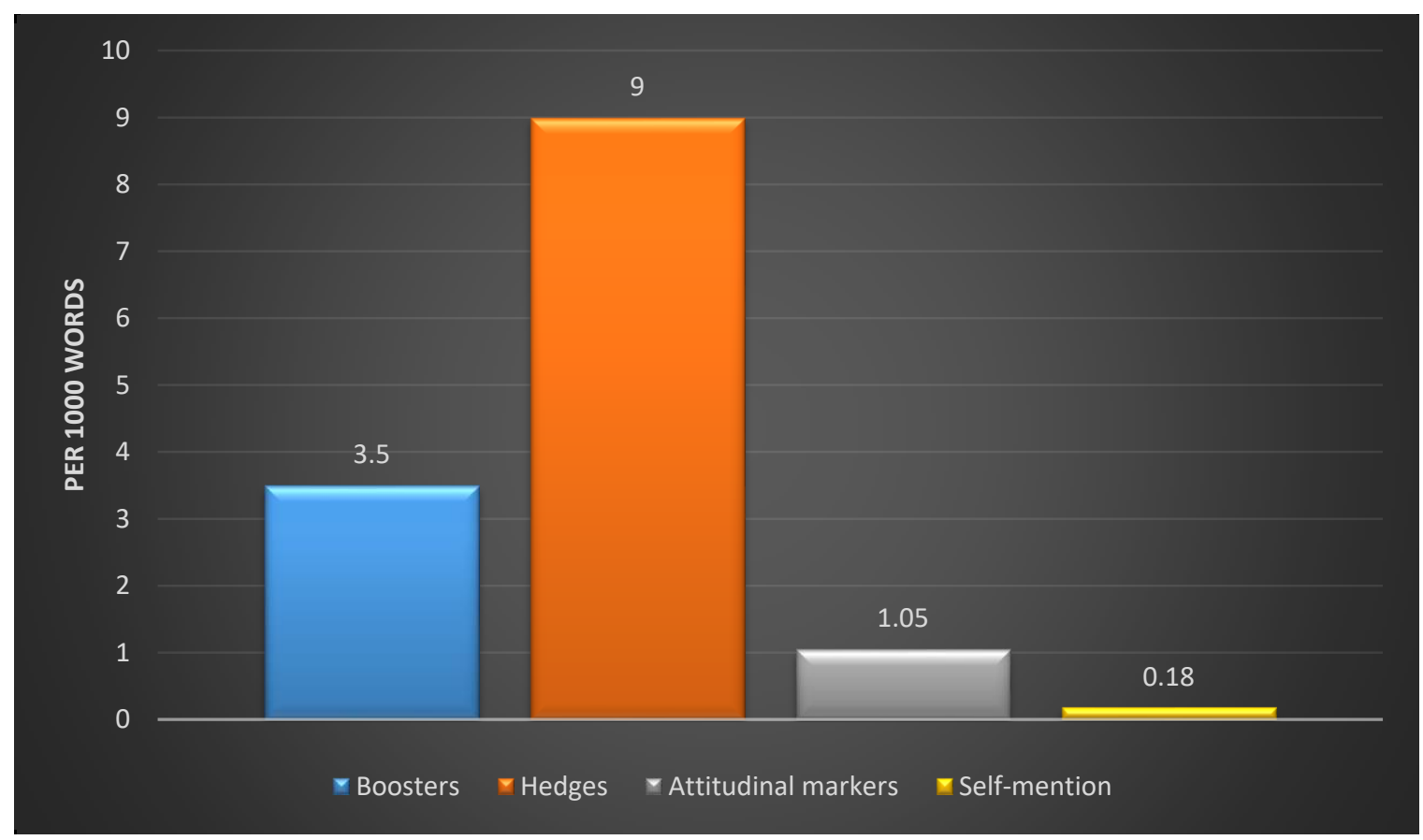

Figure 1. Overall frequency of stance linguistic features in the BUK corpus

The result in figure 1 above shows that the accounting Ph.D. authors in BUK are more frequently used hedges than other features in their theses. In the corpus, hedges have an occurrence of 9 times per 1000 words in the entire corpus, which represents $66 \%$, while boosters appear 3.5 times per 1000 words, which account for $25 \%$. In the case of attitudinal markers, the result shows that they appear 1.05 times per 1000 words, which represents $8 \%$; and explicit self-mention features occur 0.18 time per 1000 words, which accounts for $1 \%$. The result clearly indicates that the 
accounting Ph.D. authors (the BUK corpus) are frequently using hedges with a percentage of 66. For example, one of the authors says:

The loss of credibility in financial reporting indicates the existence of material weaknesses or problem along the information supply chain that deliver financial reporting to the market (Doc A3 thesis: 44).

This suggests that the accounting Ph.D. authors are expressing their own point of views in tentative ways, suggesting that they are expressing a lesser certainty regarding the informational content presented.

The results of boosters in figure 1 above show that the writers use boosters at a frequency of 3.5 per 1000 words. However, these boosters are not strong in showing absolute degree of commitment to the propositions or informational content presented in their theses. They use these features to present results of statistical figures, and reviews of previous studies rather than expressing their own point of views towards the informational contents or propositions. For example, some of the authors say:

This figure shows that many stakeholders involved ... the items are outsourced... (Doc A5 thesis: 92)

This suggests that writers are expressing themselves with quite low assertiveness towards the informational contents presented in their writing.

With regard to attitudinal markers, the results in figure 1 above show that they are using the feature at a 1.05 time in every 1000 words in Bayero University corpus. Attitudinal markers are concerned with expression of author's affective attitude. One Ph.D. author says:

An accountant would be important to coordinate accounting transaction (Doc A6 thesis: 19)

Shares of the major companies are expected to increase soon... (Doc A6 thesis: 22)

The result in figure 1 above indicates that authors are rarely used self-mention features because it has a frequency of 0.18 time per 1000 words. For example, only our and we have been used by the authors in the BUK corpus. The latter appeared 27 times, and the former occurred 15 times in the corpus. Some of the examples in the corpus are:

$\underline{W e}$ audited the annual report of the four local governments to ascertain the compliance of the requirements? (Doc A5 thesis: 7)

Our reports show that most of the commercial banks follow due process in accessing the grants... (Doc A4 thesis: 120)

These instances indicate the authors are distancing or backgrounding themselves from their work. It is unclear why they did not use a lot of explicit self-mention features. Are there epistemological issues at stake? Is the discipline of accounting particularly in this University influence by a positivist approach in the construction of knowledge? Or did the accounting Ph.D. authors intentionally avoid using it? In our institutional, disciplinary and epistemological context approach, we will explore and discuss some of these issues.

We will now make a comparison with these results and the two other corpora. The aim is to gain more insight into the use of stance linguistic features in the discipline of accounting and also to compare the distributional patterns across these corpora. Again, it will also enable us to know, through contrast, how non-native speakers of English particularly in the BUK corpus use these features. The corpora that we will use as we have mentioned in the methodology section are: UK and JAA corpora. 


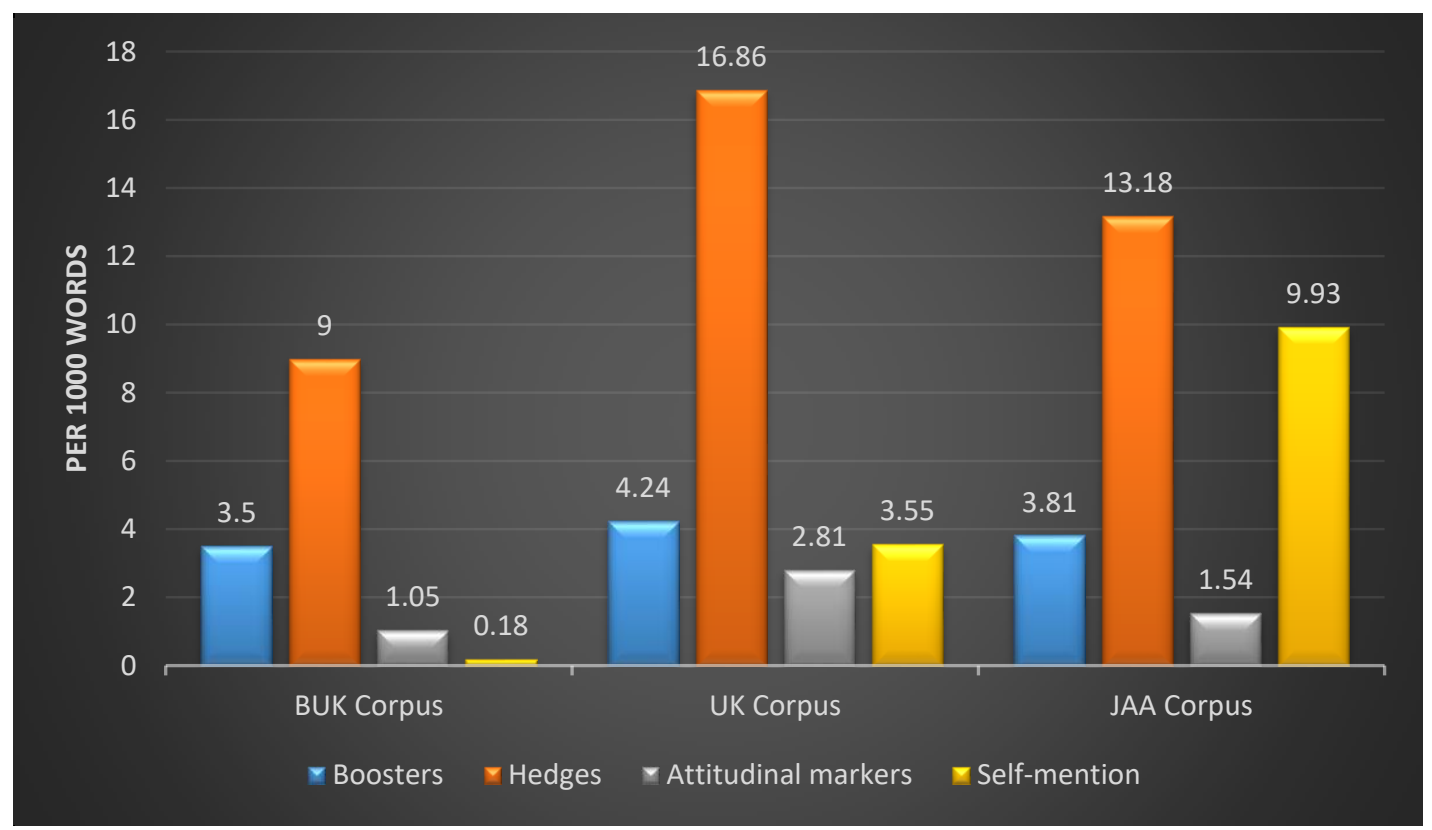

Figure 2. Overall results of stance linguistic features across the macrostructures in the three corpora

Figure 2 above shows the overall stance linguistic features across the macrostructures in the three corpora. The results show that all the three corpora are typically using hedges with a higher frequency than the other stance features categories. It indicates that hedges appeared 9 times per in the BUK corpus, while it occurred 16.68 times in the UK corpus and it appeared 13.18 times in the JAA corpus each per 1000 words. Regarding boosters, it appeared 3.5 times in the BUK corpus, while it occurred 4.24 times in the UK corpus, and appeared 3.81 times in the JAA corpus each in every 1000 words. With respect to attitudinal markers, its occurrence in the BUK corpus is 1.05 times; for UK corpus is 2.81 times, and the JAA corpus has 1.54 times of appearance. In terms of explicit self-mention features the occurrences for the three corpora are 0.18 time for BUK, 3.55 times for UK corpus and 9.93 times for JAA corpus.

The result also suggests the BUK corpus has lower frequency compared to both the JAA and UK corpora. One remarkable feature of these results however is that the BUK corpus has a lowest frequency of self-mention features which is 0.18 per 1000 words, the UK corpus has a frequency of 3.55 per 1000 words, and the JAA has a frequency of 9.93 per 1000 words. This suggests that both the UK and JAA corpora might be influenced by interpretivist approach in the construction of knowledge, which foregrounds subjectivity to a greater extent. On the other hand, the BUK corpus is probably influenced by positivist approach to knowledge, which backgrounds subjectivity. This can be seen in the frequencies of explicit self-mention across the three corpora.

Table 1. Chi-square statistic in the macrostructures across the corpora

\begin{tabular}{lllll}
\hline Stance feature & BUK & UK & JAA & TOTALS \\
\hline Boosters & $4(2.37)[1.13]$ & $4(4,73)[0.11]$ & $4(4.90)[0.17]$ & 12 \\
Hedges & $9(7.69)[0.22]$ & $17(15.38)[0.17]$ & $13(15.03)[0.54]$ & 39 \\
$\begin{array}{l}\text { Attitudinal } \\
\text { markers }\end{array}$ & $1(1.18)[0.03]$ & $3(2.37)[0.17]$ & $2(2.45)[0.08]$ & 6 \\
Self-mention & $0(2.76)[2.76]$ & $4(5.52)[0.42]$ & $10(5.72)[3.21]$ & 14 \\
Column Totals & $\mathbf{1 4}$ & $\mathbf{2 8}$ & $\mathbf{2 9}$ & $\mathbf{7 1}$ \\
\hline
\end{tabular}

The chi-square statistic is 9.0063. The p-value is .173223. The result is not significant at $\mathrm{p}<.05$.

However, in spite of visible differences across the corpora, it was considered pertinent to conduct a chi-square test to determine whether the differences are significant in terms of frequencies across the three corpora's stance linguistic features. As can be seen in table 1 above the chi-square statistic is 9.0063 and the p-value is .173223 . It shows that there is insignificant difference at $\mathrm{p}<.05$ of stance linguistic features across the three corpora. In essence the 
non-native speakers of English's corpus (BUK) use of stance linguistic features does not indicate any significant difference with the way that native speakers of English use in these two corpora.

Having presented the comparative analysis of frequencies of stance linguistic features across the three corpora, we now turn our attention to qualitative results.

\subsection{Qualitative Results}

As the results of the textual analysis shown that the accounting Ph.D. authors have been using lower frequencies of stance linguistic features, we now present the results of the contextual data, which provide more insight into why they have lower frequencies of such features.

\subsubsection{Power Relations}

One of the possible factors identified from the responses of the informants was the unequal power relations which exist between their supervisors and the authors. Their supervisors believe that the accounting Ph.D. authors are not authority in the field or discipline as such they should not use explicit self-mention features in their writing as one of the accounting Ph.D. authors says:

But one thing I think maybe a reason is just modesty and humbleness, maybe you should not be saying 'I', when you say I as if you are an authority. That is some of the understanding of the elderly scholars, if you say I they will ask you who are you. Or to say 'I' they will say who are you? Or what do you have. They feel you cannot say 'I' because you are not an authority, why not become humble (Doc author 6).

This indicates that the accounting Ph.D. authors believe that they have a lesser degree of authority than their supervisors or experts in that field to make themselves explicitly present in their writing.

4.2.2 Traditional Practices of the Department of Accounting Discouraging The Use Of Explicit Self-Mention Features

The accounting Ph.D. authors stated that their inability to use explicit self-mention features in their theses was as a result of the tradition of the Department, that authors were aware that the traditional practices of the Department and indeed the University discouraged use of explicit self-mention features as one author says:

The reason I didn't use it is because of the tradition here you cannot use such features in writing but I don't know I just came here and saw everyone was not allowed to use it. (Doc author 6).

It shows clearly that it is considered a tradition of the University that the accounting Ph.D. authors could not use explicit self-mention features. This indicates that the construction of knowledge in this University might be influenced by the implicitly or explicitly positivist approach to knowledge, which foregrounds objectivity rather than subjectivity in academic writing. This suggests that they have an unexamined understanding of the objective nature of academic writing, because their narratives suggest that 'objectivity' is to distance yourself from a research work. Again, one of the accounting Ph.D. supervisors also shares the same perceptions and beliefs as he says:

Well it is our policy here we don't allow students to use any personalised word. We used to correct them whenever they used such features, from seminar presentation, writing up theses... (Supervisor 1)

This suggests that the perceptions, beliefs and tradition of the Institution discourage writers for using self-mention features in their theses.

\subsubsection{Limited Awareness on the Use of Explicit Self-Mention Features}

The narratives of both groups of the informants suggest that there is a limited awareness of the participants that they could use explicit self-mention features in academic writing. Some of them say:

Yeah normally if you are writing the thesis arh (...) you shouldn't appear directly. You have to have a representation. There is no need to say 'I', we, you can say the study but if you say I or we you are too direct (Doc author 3).

It will make boring to keep referring to myself in my writing so is better to distance myself from the thesis (Supervisor 2)

Whenever, I'm writing paper they always asked me to stop using personalised words they believe is better not use them (Doc author 5) 
This suggests that the participants are of the belief that knowledge can be constructed objectively, if a writer does not use personal pronouns through making him/herself explicitly presence in the text. Their perception seems to be influenced by the positivist approach.

\subsubsection{Non-Teaching of Academic Writing}

In this institutional, disciplinary and epistemological context approach, the results indicate that in Bayero University and the Department there is no explicit teaching of English for specific purposes. The English for specific purposes would primarily focus on genre approach to teaching, including the use of stance linguistic features, etc. Some of the participants say:

We were not taught any of these words, I told you, I learnt them unconsciously. Here no any language teaching courses (Doc author 1).

There was no any language course that we attended. I think one of the reasons is that we were not in English language as a medium of instruction (Doc author 6).

There is no any language programme for postgraduate students. The National Universities Commission (NUC) regulates the Nigerian universities they did not mandate universities to teach any English for specific purposes for postgraduate students... (Supervisor 2).

This shows that the accounting postgraduate students learnt the use of stance linguistic features 'naturally' because there was no explicit and formal teaching of English for specific purposes. The extent of the accounting Ph.D. authors' reading and their exposure to the relevant literature in their fields assisted them to learn and use such stance linguistic features as they employed.

\section{Discussion}

\subsection{Boosters}

The results of use of boosters as can be seen in figure 1 above show that the accounting Ph.D. authors in the BUK corpus have been using boosters in their theses at a frequency of 3.5 times per 1000. However, as noted above these boosters are not strong, they have been using these features to present statistical data. This result corroborates previous studies (Hyland, 2005b; McGrath \& Kuteeva, 2012; \& Peacock, 2006).

In contrast, this result shows lower frequencies of boosters compared to other disciplines which either belong to soft pure or soft applied, we might say that the discipline of accounting in this study use lower frequencies of boosters in the construction of knowledge. In contrast, the result for boosters in Peacock's (2006) study, particularly Business Management which might say is related to both disciplines of economics and accounting, shows higher frequencies of 7.84 times per 1000 words. In other words, the accounting Ph.D. authors are expressing their point of views or positioning themselves with a lesser degree of assertiveness compared to other studies mentioned above. This foregrounds the disciplinary variation in the construction of knowledge.

\subsection{Hedges}

McGrath and Kuteeva (2012) finding indicates a lower frequency of hedges compared to this study. For example, studies such as Kondowe (2014) and Hyland (2005b) reported above show that hedge has a highest frequency compared to other features. Thus, this study shows that the accounting Ph.D. authors have been using hedges to express their own point of views with higher frequencies than other stance linguistic categories in the construction of knowledge. In other words, the accounting Ph.D. authors are positioning themselves in relatively tentative ways towards the informational contents they have presented in their academic writing.

\subsection{Attitudinal Markers}

The results of attitudinal markers reported in figure 1 show that the accounting Ph.D. authors have been using the feature of 1.05 time in every 1000 words. However, in both the UK and JAA corpora the attitudinal markers have frequencies of 2.81 and 1.54 times each per 1000 words. This suggests that the accounting Ph.D. authors used a lower frequency of the feature. Regarding the frequencies of attitudinal markers in the soft pure and soft applied disciplines, the findings of this study contradicts Hyland's (2005b) study as reported above.

\subsection{Self-mention}

The results of this feature in figure 1 above indicate that self-mention features appeared 0.18 time in every 1000 words in the BUK Corpus. This indicates that they are using it with a lower frequency, compared with the other three categories of stance linguistic features, suggesting that the authors are not frequently using self-mention features in 
the construction of knowledge. However, in the other two corpora the frequencies are higher than the BUK corpus particularly the JAA corpus which indicates a frequency of 9.93 times per 1000 words. These results in the three corpora provide a mixed view regarding use of self-mention feature in the discipline of accounting. On one hand, the result is suggesting that the discipline of accounting particularly the BUK authors are distancing themselves in their writing, which might suggest that they are influenced by positivist approach, which downplays the subjectivity in the construction of knowledge. On the other hand, it indicates that authors in the UK and JAA corpora are frequently using self-mention features in their construction of knowledge, which might suggest that they are influenced by the interpretive approach which foregrounds the subjectivity in the construction of knowledge. This study corroborates Hobbs (2014) findings that a variation might exist in the same discipline because of the individual differences. This lower frequency of self-mention features in the BUK corpus might be associated with what Hu and Cao (2011) claim that culturally preferred rhetorical strategies, epistemological beliefs' such as a positivist rather than an interpretative idea of knowledge, which might have encouraged them to avoid using self-mention feature.

Furthermore, there are institutional factors at work. In our discussion above, we have noted that the discipline of accounting might have influenced by positivist approach, although there is no any statement which could shed more light on this. However, this result of the interview sheds more light even though it does not explicitly state that both the accounting Ph.D. authors and their supervisors might have influenced by the unexamined assumptions about the notion of objectivity in academic writing of positivism. This suggests that the construction of knowledge in this Department might have influenced by the assumptions of both the accounting Ph.D. authors and their supervisor that 'objectivity' is for writers to distance themselves in academic writing.

It could be possible the absence of any programme on teaching English for specific purposes in the Department might have constrained both the groups of the informants to understand or learn that they could use personal epistemological stance in the construction of knowledge. For example, if there is an EAP/ESP programme both students and teachers could be learnt genre-sensitive academic writing skills and so on.

As the contextual data suggested that there was no English for specific courses for postgraduate, the National Universities Commission (NUC) should introduce English for specific purposes programme in the postgraduate curriculum. Having established the programme, the postgraduate students should be taught genre-sensitive, and stance linguistic features etc. rather. than only traditional grammar.

Moreover, the EAP/ESP teachers could raise the awareness of participants on the academic writing skills, which is more of genre-sensitive including teaching of stance linguistic features rather than only traditional grammar. This could probably improve the students' use of stance linguistic features and other academic writing skills.

Finally, there is a room for awareness raising among both teachers and students concerning the different epistemologies of knowledge creation circulating in their context.

\section{Conclusion}

In conclusion, we offer some insights into what stance linguistic features some of the accounting authors frequently used in their academic text. It is particularly showing us what enables or constrains the accounting Ph.D. authors in the BUK use of stance linguistic features, these factors being institutional, disciplinary and epistemological.

Future research should be focused on a large-scale study, which cuts across different genres in accounting discourse as well as native and non-native speakers of English in order to make a general conclusion on the discipline of accounting's use of stance linguistic features.

\section{References}

Afshar, H. S., Moradi, M., \& Hamzavi, R. (2014). Frequency and type of hedging devices used in the research articles of humanities, basic science and agriculture. Procedia-Social and Behavioural Sciences, 136, 70-74. https://doi.org/10.1016/j.sbspro.2014.05.290

Ahmad, U., \& M. Mehrjooseresht. (2012). Stance adverbials in Engineering thesis abstracts. Procedia-Social and Behavioural Sciences, 66, 29-36. https://doi.org/10.1016/j.sbspro.2012.11.244

Auria, C. P. (2008). Stance and academic promotionalism: a cross-disciplinary comparison in the soft sciences. Atlantis, 30(1), 129-145. https://www.jstor.org/stable/41055311

Baker, P. (2006). Using corpora in discourse analysis. Continuum.

Baynham, M. (2002). Academic writing in new and emergent discipline areas. Supporting Lifelong Learning. Routledge Falmer/Open University 
Becher, T. (1987b). Disciplinary discourse. Studies in Higher Education, 12(3), 261-274. https://doi.org/10.1080/03075078712331378052

Becher, T., \& Trowler, P. R. (2001). Academic tribes and Territories. The Society for Research into Higher Education and Open Press.

Biber, D. (2006). Stance in spoken and written university registers. Journal of English for Academic Purposes, 5(2), 97-116. https://doi.org/10.1016/j.jeap.2006.05.001

Bondi, M. (2008). Emphatics in academic discourse Integrating corpus and discourse tools. Corpora and discourse: The challenges of different settings, 31,31. https://doi.org/10.1075/scl.31.04bon

Chafe, W. L. (1986). Evidentiality in English conversation and academic writing. Ablex.

Charles, M. (2006a). The construction of stance in reporting clauses: a cross-disciplinary study of theses. Applied Linguistics, 27(3), 492-518. https://doi.org/10.1093/applin/aml021

Conrad, S., \& Biber, D. (2000). Adverbial marking of stance in speech and writing. Oxford University Press.

Creswell, J. W. (2007). Qualitative inquiry and research design: choosing among five approaches. Sage.

Crismore, A. et al. (1993). Metadiscourse in persuasive writing a study of texts written by American and Finnish university students. Written Communication, 10(1), 39-71. https://doi.org/10.1177/0741088393010001002

Du Bois, J. W. (2007). The Stance Triangle. Stancetaking in Discourse: Subjectivity, Evaluation, Interaction, ed. by Robert Englebretson, 139-182. https://doi.org/10.1075/pbns.164.07du

Ebeling, S. O., \& Wickens, P. (2012). Interpersonal themes and author stance in student writing. In English Corpus Linguistics: Looking back, Moving forward (pp. 23-40). Brill Rodopi.. https://doi.org/10.1163/9789401207478_004

Engwall, G. (1994). Not chance but choice: Criteria in corpus construction. Clarendon Press.

Fairclough, N. (1992a). Discourse and social change. Polity Press.

Gray, B., \& Biber, D. (2012). Current conceptions of stance. Stance and voice in written academic genres. Springer, 15-33. https://doi.org/10.1057/9781137030825_2

Hobbs, V. (2014). Accounting for the great divide: Features of clarity in analytic philosophy journal articles. Journal of English for Academic Purposes, 15, 27-36. https://doi.org/10.1016/j.jeap.2014.05.001

Holmes, J. (1988). Doubt and certainty in ESL textbooks. Applied Linguistics, 9(1), 21-44. https://doi.org/10.1093/applin/9.1.21

Hu, G., \& Cao, F. (2011). Hedging and booster in abstracts of applied linguistics articles: a comparative study of English-and Chinease medium journals. Journal of Pragmatics, 43(11), 2795-2809. https://doi.org/10.1016/j.pragma.2011.04.007

Hunston, S. (2000). Evaluation and the planes of discourse: status and value in persuasive texts. Oxford University Press.

Hunston, S. (2002). Corpora in applied linguistics. Cambridge University Press. https://doi.org/10.1017/CBO9781139524773

Hyland, K. (1996a). Writing without conviction? Hedging science research articles. Applied Linguistics, 17, 433-454. https://doi.org/10.1093/applin/17.4.433

Hyland, K. (1998a). Hedging in scientific research articles. Benjamins. https://doi.org/10.1075/pbns.54

Hyland, K. (1999a). Disciplinary discourses: Writer stance in research articles. Longman.

Hyland, K. (2001a). Bringing in the reader: Addressee features in academic writing. Written Communication, 18(4), 549-574. https://doi.org/10.1177\%2F0741088301018004005

Hyland, K. (2002c). Authority and invisibility: authorial identity in academic writing. Journal of Pragmatics, 34(8), 1091-1112. https://doi.org/10.1016/S0378-2166(02)00035-8

Hyland, K. (2005a). Metadiscourse. Continuum.

Hyland, K. (2005b). Stance and engagement: A model of interaction in academic discourse. Discourse Studies, 7(2), 173-192. https://doi.org/10.1177\%2F1461445605050365 
Hyland, K. (2005c). Metadiscourse exploring interaction in writing. Continuum.

Hyland, K. (2007). Disciplinary discourse: social interactions in academic writing. The University of Michigan Press.

Kennedy, G. (2014). An introduction to corpus linguistics. Routledge. https://doi.org/10.4324/9781315843674

Kondowe, W. (2014). Hedging and Boosting as Interactional Metadiscourse in Literature Doctoral Dissertation Abstracts. International Journal of Language Learning and Applied Linguistics World. 214-221.

Laura, L. A., \& Lancaster, Z. (2014). Linguistic markers of stance in early and advanced academic writing: a corpus-based comparison. Written $\quad$ Communication, $31(2), \quad$ 151-183. https://doi.org/10.1177\%2F0741088314527055

Martin, J. R. (2000). Beyond exchange: Appraisal systems in English. Oxford University Press.

McGrath, L. (2016). Self-mentions in anthropology and history research articles: Variation between and within disciplines. Journal of English for Academic Purposes, 21, 86-98. https://doi.org/10.1016/j.jeap.2015.11.004

McGrath, L., \& Kuteeva., M. (2012). Stance and engagement in pure mathematics research articles: linking discourse features to disciplinary practices. English for Specific Purposes, 31, 161-173. https://doi.org/10.1016/j.esp.2011.11.002

Miles, M. B., \& Huberman, A. M. (1984). Qualitative data analysis: A sourcebook of new methods. Sage Publications

Nivales, M. (2011). Hedging in college research papers: Implications for language instruction. Asian EFL Journal, $52,35-45$.

Peacock, M. (2006). A cross-disciplinary comparison of boosting in research articles. Corpora, 1(1), 61-84. https://doi.org/10.3366/cor.2006.1.1.61

Pho, P. D. (2008). Research article abstracts in applied linguistics and educational technology: a study of linguistic realizations of rhetorical structure and authorial stance. Discourse Studies, 10(2), 231-250. https://doi.org/10.1177\%2F1461445607087010

Scott, M. (1997). WordSmith tools manual.

Scott, M. (2004). Oxford WordSmith Tools version 4. Oxford University Press.

Scott, M., \& Tribble, C. (2006). Textual patterns: Key words and corpus analysis in language education. John Benjamins Publishing. https://doi.org/10.1075/scl.22

Shehzad, W. (2007). Explicit author in the scientific discourse: A corpus-based study of the author's voice. Malaysian Journal of ELT Research, 3, 56-73.

Silver, M. (2003). The stance of stance: a critical look at ways stance is expressed and modeled in academic discourse. Journal of English for Academic Purposes, 2, 359-374. https://doi.org/10.1016/S1475-1585(03)00051-1

Stubbs, M. (1996). Text and corpus analysis. Blackwell.

Swales, J. (1990). Genre analysis: English in academic and research settings. Cambrideg University Press.

Swales, J. (1998a). Textography: Toward a contextualization of written academic discourse. Research on Language and Social Interaction, 31(1), 109-121. https://doi.org/10.1207/s15327973rlsi3101_7

Thompson, P., \& Tripple, C. (2001). Looking at citations: Using corpora in English for academic purposes. Language Learning and Technology, 5(3), 91-105.

Widdowson., H. G. (1998). Context, community and authentic language. TESOL Quarterly, 32(4), 705-716. https://doi.org/10.2307/3588001 


\section{Appendix}

Hyland's stance linguistic features:

\begin{tabular}{|c|c|c|c|}
\hline Boosters & Hedges & Attitudinal markers & Self-mention \\
\hline actually & about & admittedly & I \\
\hline always & almost & agree & we \\
\hline believe & apparent & amaze & me \\
\hline beyond doubt & appear & appropriate & my \\
\hline certain & approximately & astonish & our \\
\hline clear & argue & correctly & mine \\
\hline conclusively & around & curious & us \\
\hline decidedly & assume & desirable & the author \\
\hline definite & broadly & disappointed & the writer \\
\hline demonstrate & certain amount & disagree & \\
\hline doubtless & certain extent & dramatic & \\
\hline establish & certain level & essential & \\
\hline evident & claim & even $\mathrm{x}$ & \\
\hline find & could & expected & \\
\hline in fact & couldn't & fortunate & \\
\hline incontestable & doubt & hopeful & \\
\hline incontrovertible & essentially & important & \\
\hline indeed & estimate & inappropriate & \\
\hline indisputable & fairly & interesting & \\
\hline know & feel & prefer & \\
\hline must (possibility] & frequently & remarkable & \\
\hline never & from my perspective & shock & \\
\hline no doubt & from our perspective & striking & \\
\hline obvious & from this perspective & surprised & \\
\hline of course & generally & surprising & \\
\hline prove & guess & unbelievable & \\
\hline realize & indicate & understandable & \\
\hline really & in general & unexpectedly & \\
\hline show & in most cases & unfortunate & \\
\hline sure & in most instances & unusual & \\
\hline surely & in my opinion & & \\
\hline think & in my view & & \\
\hline true & in this view & & \\
\hline undeniable & in our opinion & & \\
\hline undisputedly & in our view & & \\
\hline undoubtedly & largely & & \\
\hline \multirow[t]{2}{*}{ without doubt } & likely & & \\
\hline & mainly & & \\
\hline
\end{tabular}




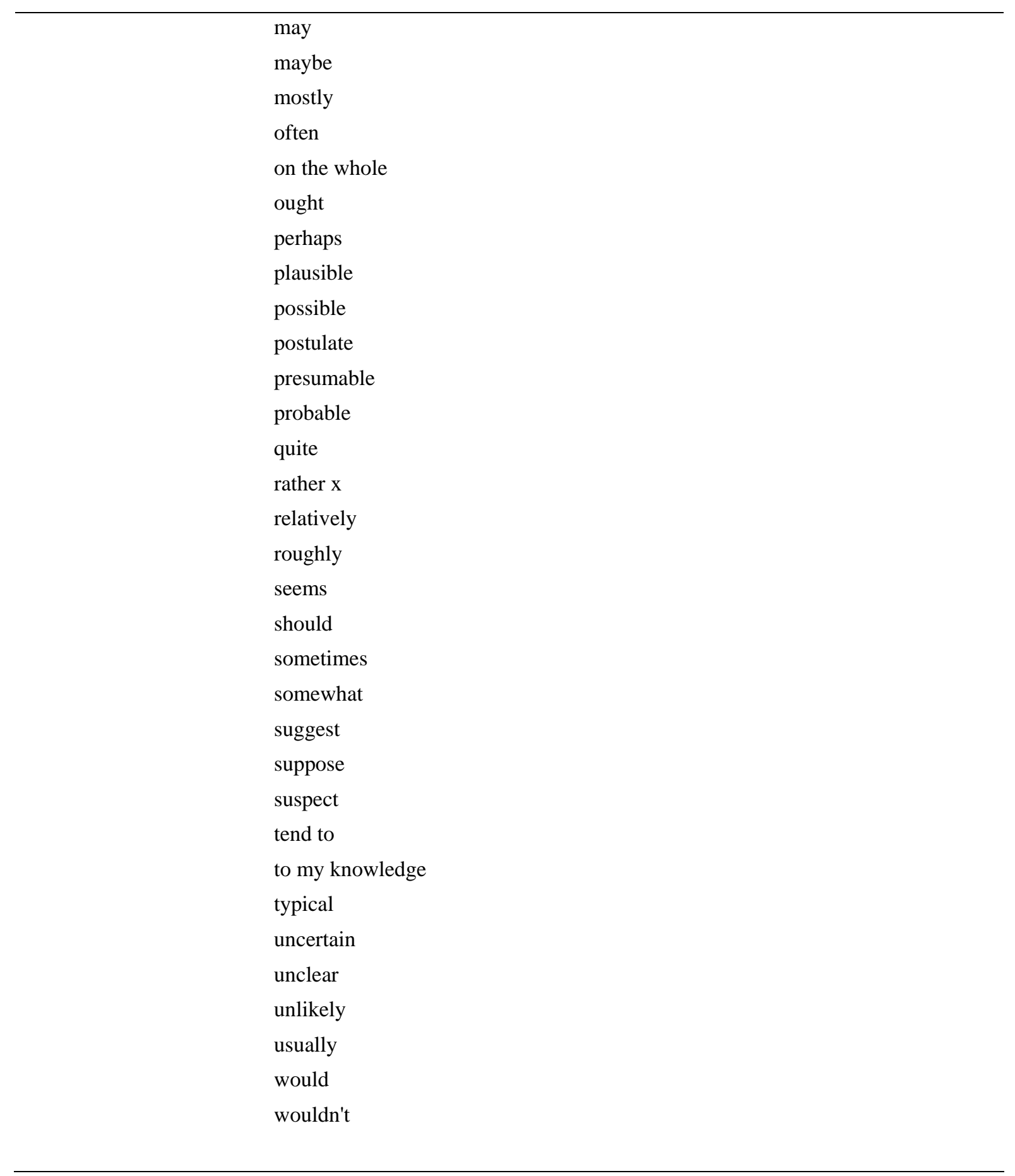

\section{Copyrights}

Copyright for this article is retained by the author(s), with first publication rights granted to the journal.

This is an open-access article distributed under the terms and conditions of the Creative Commons Attribution license (http://creativecommons.org/licenses/by/4.0/). 